\title{
Influential Factors and Determination of strength of in-situ concrete, using twist-off method
}

Factores influyentes y determinación de la resistencia del hormigón in situ, utilizando

método de giro

Author:

Pooria Najarbashi ${ }^{1}$

Mahmoud Naderi ${ }^{2}$

\section{SCIENTIFIC RESEARCH}

How to cite this paper:

Najarbashi. P., Naderi. M. Influential Factors and Determination of strength of in-situ concrete, using twist-off method Tittle of paper, Qazvin. Iran. Innovaciencia. 2019; 7 (2): 1-9. DOI: http://dx.doi.org/10.15649/2346075X.766

Reception date:

Received: 03 March 2019

Accepted: 2 May 2019

Published: 25 October 2019

Keywords:

Concrete strength; In-situ testing; Twist-off method

\begin{abstract}
Concrete strength represents by far the most critical property of concrete. It represents the mechanical properties of concrete. On-site evaluation of concrete strength remains the fundamental challenge in the condition assessment of existing infrastructure. Although standard laboratory methods can be typically used but most of these testing methods are costly and time-consuming. Among the in-situ methods, the "twist-off" method with very slight damage is genuinely a convenient, fast and also low-cost technique that provides accurate results for engineers. In this study, the twist-off method has been used for the assessment of in-situ strength of the 30 concrete structures in Qazvin in Iran. The results showed structures studied had a strength of 45 to $600 \mathrm{~kg} / \mathrm{cm} 2$ and the average is about $200 \mathrm{~kg} / \mathrm{cm} 2$. The observed variation is very high, as well as a significant difference between the compressive strength of the columns, and the floors of the buildings that all indicate non-standard concrete mixing and inadequate control over construction. However, according to the past experience and results of the samples, some recommendations in this regard have been suggested.
\end{abstract}

1 Master of Science, Dept. of Civil Engineering, Imam Khomeini Int, Qazvin. Iran. Email: poorianajar@gmail.com

2 Professor, Dept. of Civil Engineering, Imam Khomeini Int University, Qazvin. Iran 


\section{INTRODUCTION}

For over 70 years, the most widely used test for concrete has been the compression test of the standard cylinder. The test procedure is relatively easy to perform in terms of sampling, preparation of specimens, and the evaluation of strength but since 1960, the in-situ methods of hardened concrete have been scientifically studied ${ }^{[1]}$.

The necessity of the potential emergence and development of these preferred methods originates from a considerable increase in the number of concrete structures and unexpected damages observed in newly constructed concrete structures. The reason for these possible damages can be, high water-cement ratio, inhomogeneous properties and inappropriate mix of concrete, the increasing use of additives, difference between properties of an actual concrete used in structure and the one used for the samples, low-quality control during production of concrete and the last but the most important one, significant difference between ideal standard guidelines and the non-standard implementation of fieldwork methods. To achieve reasonably the result of a common concrete cubic strength, 28 days of aged concrete specimens are needed, and when carried out according to standard procedures, however, the cylinder test only represents the potential strength of the concrete as delivered to a site. The standard test is used mainly as a basis for quality control to assure those contract requirements are met. It is not intended for determining the in-situ strength of the concrete, since it makes no allowance for the effects of placing, compaction or curing and it is unusual for the concrete in a structure to have the same properties as a standard-cured cylinder at the same test age. In addition, since standard-cured cylinders are usually tested at an age of 28 days, they cannot be used to determine whether adequate strength exists at earlier ages for safe removal of formwork ${ }^{[2]}$.
However, the result just only indicates that the concrete is suitable for possible use and does not provide engineers enough information about the actual building conditions after construction. According to the aforementioned reasons, in addition to the necessity of the existence of laboratory methods, there should be methods for accurately determining the compressive strength of in-situ concrete.

The key is to understand deeply both concept and implementing of laboratory and in-situ methods. There is enough familiarity with laboratory methods, but most engineers traditionally believe that in-situ concrete methods are very specialized and are not aware of the validity of commonly used methods and hand it over to experts. Although the implementation and interpretation of test results are important to be analyzed by experienced professionals, but the main problems are that the existing and newly established methods which they can be expanded and used in the future have not been sufficiently considered and reviewed. Common laboratory methods for assessing the compressive strength of concrete such as cubes and cylindrical specimens are available in enough details in various design codes and standards. Most of the design codes recommend cylinder or concrete cube as the standard test procedure. Standard guidelines for the application and interpretation of cube procedure have been accurately described in specific details in British standard Part BS1881-116 [3] and the cylindrical method has been described in ASTM standard C39-94 ${ }^{[4]}$.

There are three major types of in-situ test methods; Non-destructive, partially destructive and destructive test methods which in the non-destructive, there is no damage to the concrete's specimen. In partially destructive tests category, such as core testing, pullout ${ }^{[5,6]}$, pull off ${ }^{[7]}$ and break-off ${ }^{[8,9]}$ tests, the concrete surface is damaged slightly, which needs minor repairing after the standard procedure ${ }^{[10]}$. 
The destructive methods estimate the most reliable strength, which needs the necessary parts of the concrete to be gently removed, by sawing or coring and then testing specimens in a laboratory by a relevant standard. In the destructive group, specific guidelines for the drilled cores can be found in ASTM C42-94 $\stackrel{[11]}{ }$, British Standard Part BS1881-120 [12] and ASTM C318 standard ${ }^{[13]}$.

\section{LABORATORY METHODS FOR DETERMINING THE STRENGTH OF CONCRETE}

\subsection{Concrete Cylinder Compression Testing}

The standard method of this specific test is accurately described in American Standard ASTM C31 ${ }^{[14]}$, C39 ${ }^{[4]}$, C617 ${ }^{[15]}$ which can be used for determining the compressive strength of cylinders and cores specimens. In this test, a compressive axial load is applied to molded cylinders or cores at the proper speed recommended in the standard until failure occurs. The compressive strength of the specimen is typically calculated by dividing the maximum load achieved during the test by the cross-sectional area of the specimen. The load should be applied on the specimen continuously at a rate of movement corresponding to the design code and the loading rate should be unchanged during the test. The results of this test method are used as a basis for quality control of concrete and other criteria. The maximum load carried by the sample during the test typically depends on the specimen size, moisture condition, degree of consolidation, and length to diameter ratio, curing, and treatment of the samples. The test should be continuing until the selected sample fails and displays a well-defined fracture. The final load, the type of failure and the apparent condition of the concrete are accurately noted.

\subsection{Test Method for Compressive Strength of Concrete Cylinders Cast in Place in Cylindrical Molds}

This test is accurately described in the ASTM C87394 [16]. This test method is limited to use in slabs where the depth of concrete is from 125 to 300 $\mathrm{mm}$. Cast-in-place molds shall have a diameter at least three times the nominal maximum aggregate size. The ratio of the length-to-diameter (L/D) of the specimen after capping shall not be less than 1.0 and should preferably be between 1.5 and 2.0. Molds (inner member) shall be constructed in one piece in the form of exact circular cylinders at least $100 \mathrm{~mm}$. Molds shall be watertight and meet the criteria of the section on water leakage of Specification C 470 [17]. The specimens should be subjected to the same cures and treatment as provided to the surrounding concrete. Specimen molds shall remain fully seated in place until the time of removal for transportation to the testing location. Molds should be gently removed from support members and care must be taken so not to physically damage specimens. From the time of removal from the structure until the time of the test, specimens should be properly maintained at a standard temperature of $6^{\circ} \mathrm{C}$ of the slab surface temperature. Transportation to the laboratory shall occur within 4 hour after removal. Cap specimens should be in accordance with Practice ASTM C617 ${ }^{[15]}$ and test in accordance with ASTM C39 [4]. The reported compressive strength is corrected based on the length to diameter ratio by multiplying the uncorrected strength by the nearest applicable correction factor in the section of the ASTM C4294 [11].

\section{IN-PLACE METHODS TO ESTIMATE CONCRETE STRENGTH}

Test methods for determining the strength of concrete are classified into three categories of nondestructive, partially destructive and destructive methods ${ }^{[1,18]}$. Non-destructive methods like rebound hammer test $\frac{[19,20]}{}$ and ultrasonic test do not damage to the samples. Rebound hammer test is classified as a hardness test and is based on the principle that the rebound of an elastic mass depends on the hardness of the surface against which the mass impinges. Ultrasonic test has been described in ASTM C 597$83{ }^{[21]}$ and BS1881:203 ${ }^{[22]}$. This efficient method of testing also helps to properly investigate microcracks, crack depth, and deterioration of concrete.

Leshchinsky summarized the key advantages of nondestructive tests ${ }^{[23]}$. In a destructive group, specific 
tests are carried out to the point of specimens failing which these methods bear the most exact results of the concrete strength. In a number of ways, the specimens are needed to cut or sawed to be tested in the laboratory. The standard crushing of the specimens is the usual manner test to assess the strength of concrete.

Surface hardness test has the least damage in the test and are low-cost and fast. These non-destructive testing of concrete are a very simple method of testing but it requires skilled and experienced persons having some special knowledge to interpret and analyze test results. Core tests are valid in accurately assessing the strength of concrete, but they do the most damaging, very slow and costly. Partially destructive methods generally need to be calibrated and leave a minor damage. In this method, the targeted surface area is just examined and the variability of results of this method is high. The partially destructive method can be implemented as an initial test and be completed by other methods. Whenever there is, only one side of the concrete surface is available to be investigated. Penetration techniques are fast and appropriate, but for smaller members, pullout and twist-off tests are more appropriate tests.

\subsection{Twist-off method}

The "twist-off " test is a partially destructive test and does not require any prior planning for testing. The only thing needed just a available side of concrete sample. The good features of this method can be the proper precision, fast, low cost compare to other methods and more importantly, very small amount of damage left by the test. As is shown in Fig. 1, the method involves bonding a $40 \mathrm{~mm}$ diameter metal probe to the surface of concrete and a torque-meter is then situated on the preformed groove on the probe and a gradually increasing torque is applied by hand. Using the shear stress-torque relationship, the failure torsional shear stress is calculated. This can be used to estimate the concrete's equivalent cube compressive strength by means of a previously prepared calibration graph. There is no need to remove and transfer the sample to the laboratory. As it is obvious, no pre-drilling of the sample is required and the test is carried out by the use of adhesively bonded probe which means less work and damage to the concrete surface. The epoxy adhesives used must have a high resistance to be able to properly and sufficiently bond between the metal disc and the concrete surface. Before using epoxy adhesive, the surface of concrete and metal disks must be clean and free of any excess materials. After attaching the concrete to the metal disc by using adhesive, the excess adhesive around the metal disc must be removed and cleaned so that the diameter of the adhesive surface with the metal disc diameter both be $4 \mathrm{~cm}$ on the concrete sample. Figure 2 shows the overall view of the twist-off test. Twist-off test can be done after 24 hours of bonding. The concrete sample should be placed firmly so that the specimen does not move when the torque-meter is rotated, otherwise the test results will not be correct.

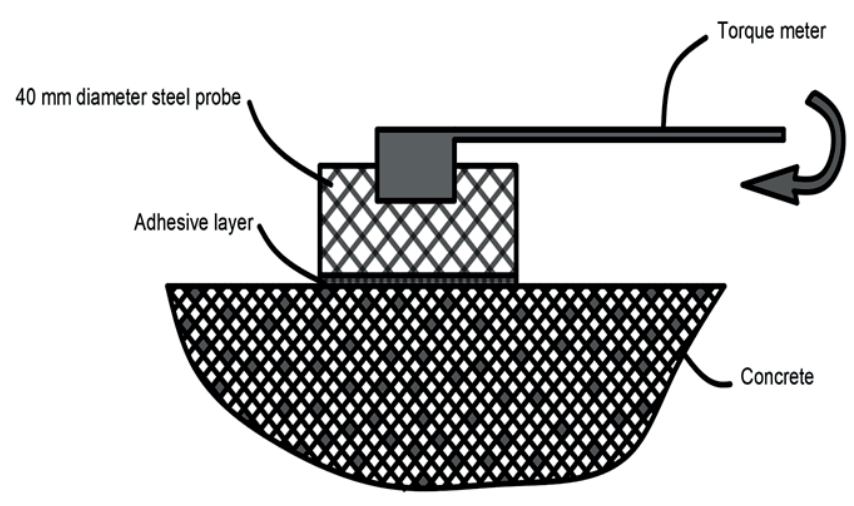

Figure.1. Twist-off method

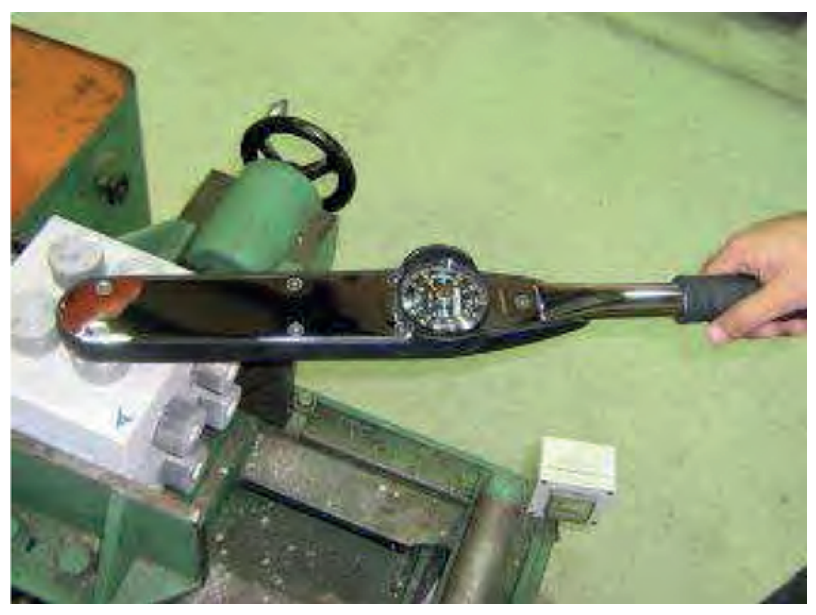

Figure 2. Applying torsion by torque-meter device 


\section{EXPERIMENT}

With necessary coordination and consultation of local authorities in the Qazvin, 30 concrete structures were carefully selected and it was decided that to collect five samples from each structure by the twist-off method which the manner and procedure described in section 3.1. While in most cases, good welcome enthusiastically received but, in some cases, there were problems that delayed the ongoing work for some time, and, even more, the test was prevented by the field workers. The cubic samples are arranged in $15 \times 15 \times 15 \mathrm{~cm}$ dimensions according to BS 1881 standard ${ }^{[3]}$.

\section{RESULTS AND DISCUSSION}

The results obtained from the sampling by the twistoff method for each of the 30 selected structures are plotted in figure 3,4,5. The results of the experiments show that the compressive strength of the concrete structures investigated is between 45 and $600 \mathrm{~kg} /$ $\mathrm{cm}^{2}$. The average compressive strength is $203.5 \mathrm{~kg} /$ $\mathrm{cm}^{2}$, as it is clearly the range of compressive strength is unusually wide. By study, the concrete members samples indicate that the floors strength is much more than the strength of the columns since floor curing is usually easier that columns, it can be concluded that not enough precision and afford have been put in compacting and curing the columns concrete.

Another important point that can be seen from the results there is a significant difference between the strength of different members of the structure, which remind the possibility of bad mixing of concrete, improper performance as well as lack of monitoring applied to the structure. Although for some reason, it was impossible to carefully examine the concrete materials, transportation, pouring, compression and curing of concrete, but by brief reviews of the weakness of the prepared concrete, it can find out that batching concrete have less strength compare to in-place concrete which that is a highly unusual. Unfortunately, should not forget that it is a common practice to add more water into concrete mixing to increase its strength which certainly, has a harmful impact on the concrete.

Also, the comparison between three sample strength for "beams", "floors" and "columns" groups, it can be concluded that the average compressive strength obtained for beams and floors and columns is 210, 137, and $223 \mathrm{~kg} / \mathrm{cm}^{2}$, respectively, indicating a significant decrease in the strength of floors. This marked reduction in strength can be attributed to an inadequate and improper concrete curing, most of which happen for slabs and floors that have a wide exposed surface that have more water evaporation compare to others.

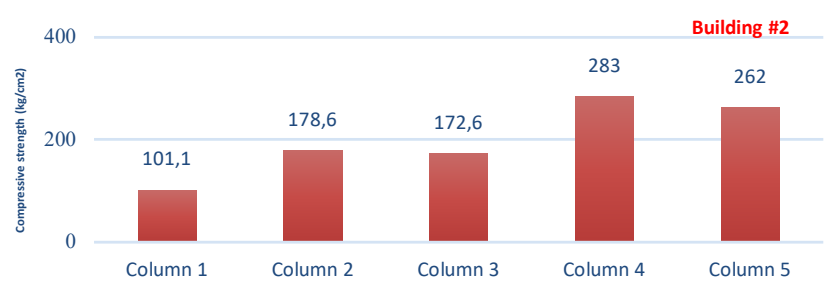

Figure 3. Compressive strength of concrete samples of buildings 1-2 

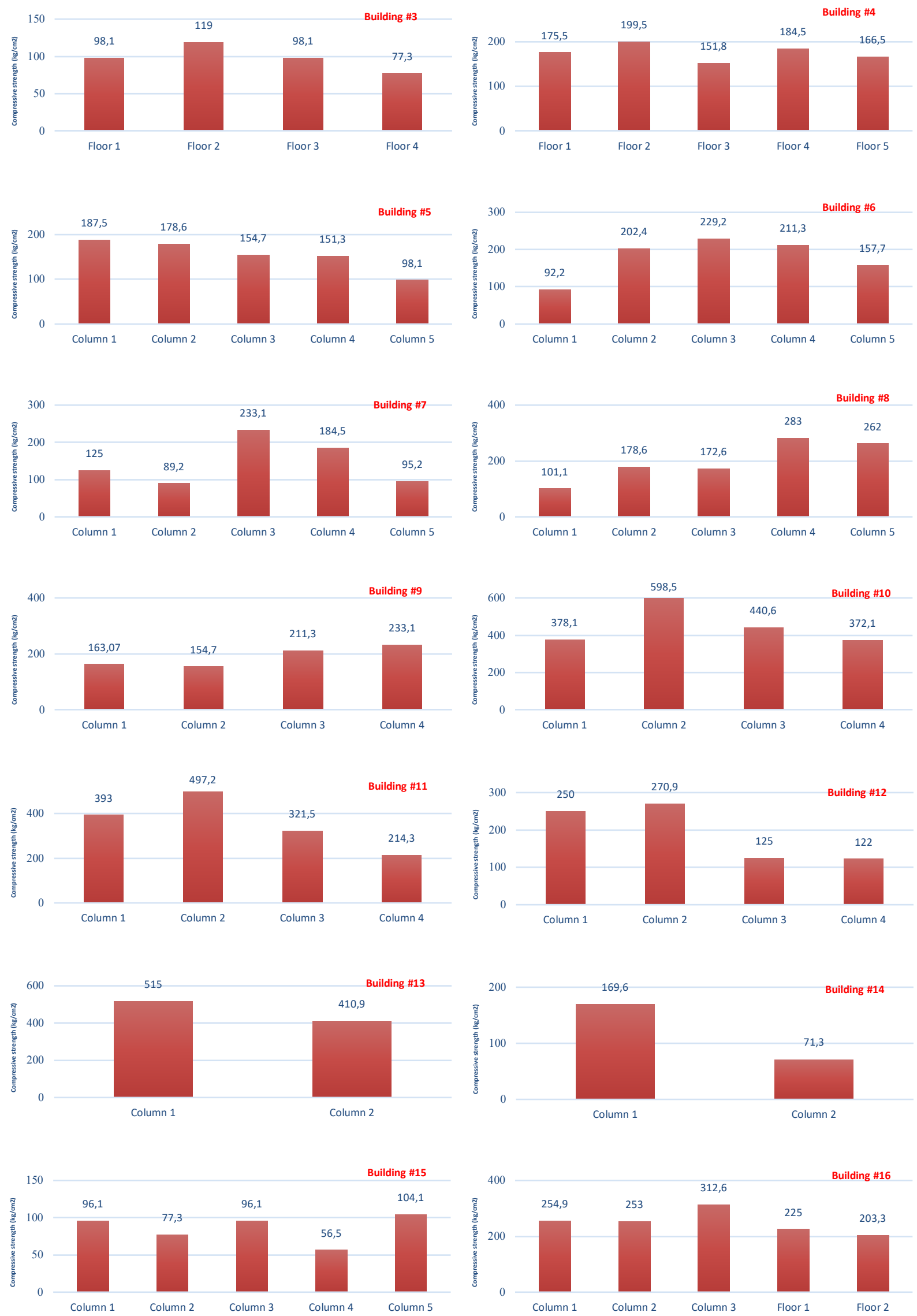

Figure 4. Compressive strength of concrete samples of buildings 3-18 

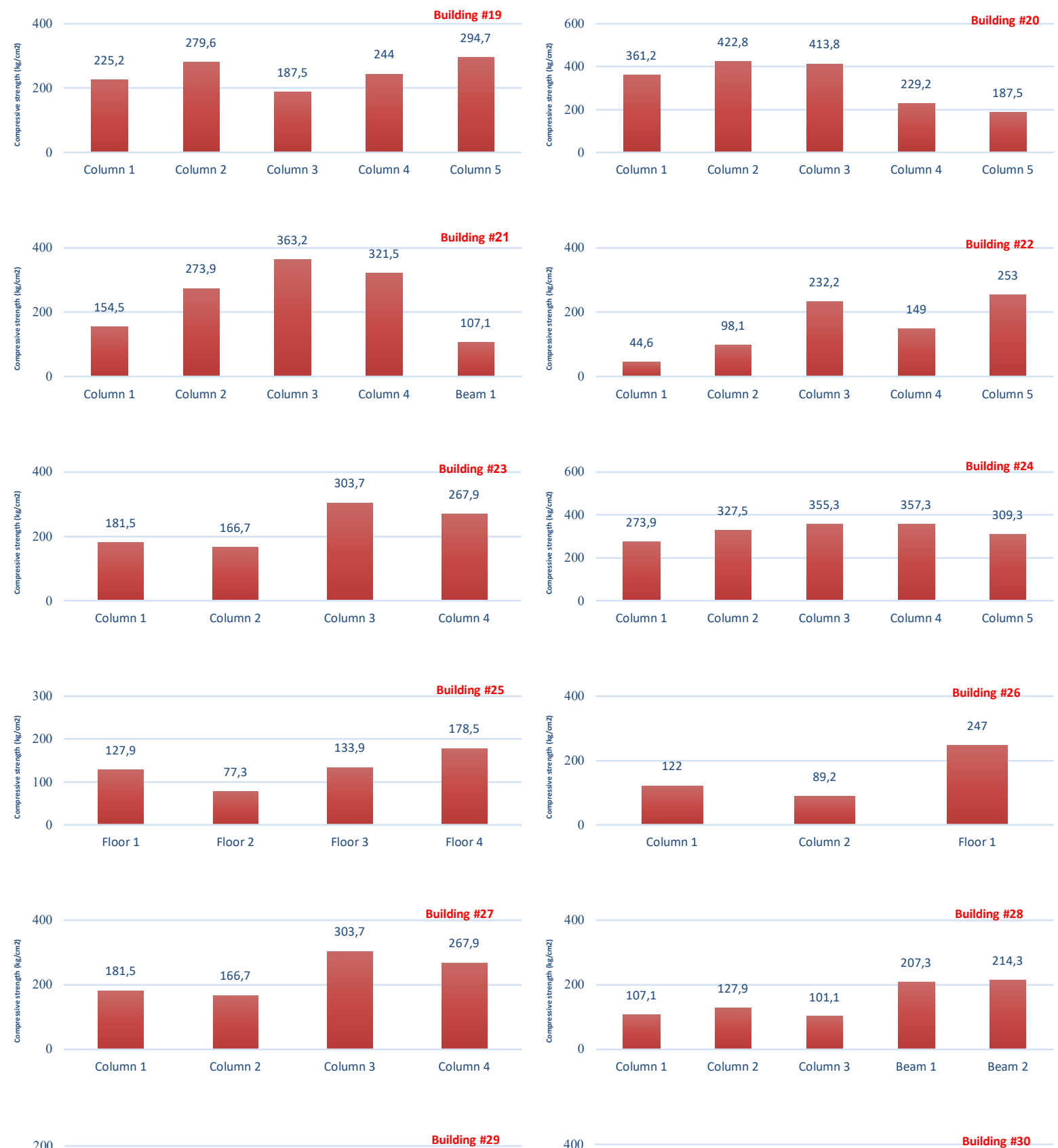

Figure 5. Compressive strength of concrete samples of buildings 19-30

\section{CONCLUSION}

In this research, in order to investigate the compressive strength of in-situ concrete used in construction, 30 concrete buildings in the Qazvin were selected and samples were collected by the twist-off method. On the basis of the charts and result were gained by the samples, the following conclusions have been reached:
1. The difference between measured strengths (500 $\mathrm{kg} / \mathrm{cm}^{2}$ ) is significantly high, which indicates concrete curing was not carried out properly.

2. There is a wide range of concrete strength in the city is about 45 to $600 \mathrm{~kg} / \mathrm{cm}^{2}$, expresses these issues that: 
(A) In the proper preparation and application of concrete, no acceptable monitoring has been carried out.

(B) The equipment utilized is completely different.

(C) Standard controls do not apply to materials manufacturing, transportation, and processing.

3. The considerable increase of strength in some of the tested structures is due to the increase of concrete cement ratio, since the cost of cement production, as well as its adverse effects on the environment, indicate inadequate training and profound lack of necessary skills in this industry.

4. Comparison of the strength obtained for structural groups of "beams", "floors" and "columns", shows that the average compressive strength is 210,137 and $223 \mathrm{~kg} / \mathrm{cm}^{2}$ respectively, indicating a significant reduction in the strength of concrete floors. This reduction in strength can be attributed to an inadequate concrete curing, which frequently involves exposed concrete surfaces, like slabs and floors which surface water evaporation ratio is much more than other parts.

According to the results, the following suggestions and possible solutions can be considered as a solution to solve efficiently these fundamental weaknesses and problems in the engineering development system:

1. Appropriate and compulsory vocational courses are considered for all executive and fieldworkers and only allowed to work if they are satisfactorily completed the courses.

2. Properties of concrete materials used for production should be carefully examined and adapted to acceptable standards.

3. The mixing design methods, transporting, compaction and curing are adequately controlled and approved.

4. An increase of strength in some of the tested structures is due to the increase of concrete cement ratio, since the cost of cement production, as well as its bad effects on the environment, indicate inadequate training and lack of necessary skills in this industry.

\section{REFERENCES}

1. Bungey, J.H., and Millard, S.G. (1996), "Testing of concrete in structures. Blackie Academic and Professional" London. https://doi. org/10.4324/9780203487839

2. Carino Chairman, "In-place methods to estimate concrete strength", Reported by ACI committee 228.

3. BS188: Part 116, (1983), "Method for determination of the compressive strength of concrete cubes", British Standards Institution, London.

4. ASTM C39: Part 94, (2018), "Standard test method for compressive strength of cylindrical concrete specimens", ASTM International, West Conshohocken, PA, 2018.

5. BaalbakI., W., Aitcin, P.V., and Ballivy, G. (1992). "On predicting modulus of elasticity in highstrength concrete".

6. ASTM C900-15, "Standard Test Method for Pullout Strength of Hardened Concrete", ASTM International, West Conshohocken, PA, 2015.

7. Long, A.E., Murray, A.Mc.C., (1984), “The pulloff partially destructive test for concrete", Spec. Publ. SP82, 17, American Concrete Institute, Detroit, 327-350.

8. Johansen, R., (1975), "In-situ strength evaluation of concrete-the "break-off" method", Concrete International, 1, No.9, 45-51.

9. ASTM C1150-96, 1996, "Standard Test Method for the Break-Off Number of Concrete" (Withdrawn 2002), ASTM International, West Conshohocken, PA, ,

10. Jedidi Malek, Machta Kaouther, (2014),'Destructive and Non-destructive Testing of Concrete Structures".

11. ASTM C42: Part 94, (1995), "Standard test method of obtaining and testing drilled cores and sawed beams of concrete", American Society for Testing and Materials, Philadelphia. An annual book. 
12. BS188: Part 120, (1983), "Method for determination of the compressive strength of concrete cores", British Standards Institution, London.

13. ASTM C318, (2018), "Building code requirements for structural concrete and commentary", American Society for Testing and Materials, West Conshohocken, PA.

14. ASTM C31, (2019), "Standard Practice for Making and Curing Concrete Test Specimens in the Field", West Conshohocken, PA,

15. ASTM C617, "Standard Practice for Capping Cylindrical Concrete Specimens", ASTM International, West Conshohocken, PA, 2015.

16. ASTM C873: Part 94, (2015), "Standard Test Method for Compressive Strength of Concrete Cylinders Cast in Place in Cylindrical Molds", American Society for Testing and Materials, West Conshohocken, PA.

17. ASTM C470, (2015), "Standard Specification for Molds for Forming Concrete Test Cylinders Vertically" American Society for Testing and Materials, West Conshohocken, PA.

18. Malhotra, V.M., Carino, Nicholas J., (2003), "Handbook on Nondestructive Testing of Concrete" CRC Press; Second edition.

https://doi.org/10.1201/9781420040050

19. ASTM C 805-85, “Test for Rebound Number of Hardened Concrete", U.S.A., 1993.

20. BS 1881: Part 202, 1986: Recommendations for Surface Hardness Tests by the Rebound Hammer, BSI, U.K., 1986.

21. ASTM C 597-83 (Reapproved 1991), "Test for Pulse Velocity Through Concrete", U.S.A.

22. BS 1881: Part 203, 1986, "Measurement of Velocity of Ultrasonic Pulses in Concrete", BSI, U.K.

23. Leshchinsky, 2000, "concrete strength by combined non-destructive methods simply and reliably predicted".

24. Mahmood Naderi, "Assessing the in situ strength of concrete, using new twist-off method". 